\title{
Physical activity for blood glucose control in gestational diabetes mellitus: rationale and recommendations for translational behavioral interventions
}

Oluwafemifola Onaade ${ }^{1 *}$ D, Jill M. Maples², Bethany Rand ${ }^{1}$, Kimberly B. Fortner ${ }^{2}$, Nikki B. Zite ${ }^{2}$ and Samantha F. Ehrlich ${ }^{1}$

\begin{abstract}
Gestational Diabetes Mellitus (GDM) is associated with adverse health outcomes during pregnancy and beyond. Previous randomized controlled trials of exercise interventions have demonstrated that exercise, conducted primarily during supervised sessions, improves maternal glycemic control in women with GDM. However, additional research is needed to develop physical activity interventions that are easily implemented in healthcare settings (e.g., recommendations and strategies to increase non-supervised physical activity). This narrative review presents: current physical activity recommendations for pregnancy and women with GDM; the scientific literature to date on physical activity, particularly walking, and blood glucose control in GDM; rationale for physical activity interventions targeting women with GDM that are appropriate for translation to the clinical setting (e.g., lifestyle interventions that include behavioral counseling with a health coach); and the strategies employed by previous, successful lifestyle interventions for pregnant and postpartum women that were based in clinical settings.

Most previous exercise interventions for blood glucose control in women with GDM have included supervised exercise sessions, and will thus be difficult to translate to the health care system. However, lifestyle interventions for weight maintenance (i.e., healthy diet and physical activity) set in the health care system and delivered by health coaches have been successfully implemented in pregnant and postpartum populations. Therefore, we suggest that future trials examine lifestyle interventions that promote unsupervised walking with evidence-based behavioral strategies (e.g., goal setting, monitoring, and feedback) and consider incorporating the use of physical activity tracking devices to support these strategies.
\end{abstract}

Keywords: Gestational diabetes, Behavioral intervention, Lifestyle counseling, Physical activity, Walking

\footnotetext{
* Correspondence: oonaade@utk.edu

'Department of Public Health, The University of Tennessee, 369 HPER, 1914 Andy Holt Ave., TN 37996 Knoxville, USA

Full list of author information is available at the end of the article
}

(c) The Author(s). 2021 Open Access This article is licensed under a Creative Commons Attribution 4.0 International License, which permits use, sharing, adaptation, distribution and reproduction in any medium or format, as long as you give appropriate credit to the original author(s) and the source, provide a link to the Creative Commons licence, and indicate if changes were made. The images or other third party material in this article are included in the article's Creative Commons licence, unless indicated otherwise in a credit line to the material. If material is not included in the article's Creative Commons licence and your intended use is not permitted by statutory regulation or exceeds the permitted use, you will need to obtain permission directly from the copyright holder. To view a copy of this licence, visit http://creativecommons.org/licenses/by/4.0/ The Creative Commons Public Domain Dedication waiver (http://creativecommons.org/publicdomain/zero/1.0/) applies to the data made available in this article, unless otherwise stated in a credit line to the data. 


\section{Background}

Gestational Diabetes Mellitus (GDM) is defined as glucose intolerance first recognized during pregnancy [1]. In 2016, the prevalence of GDM in the United States was about $6 \%$ [2], with increases anticipated, given the on-going obesity epidemic [3]. Poorly controlled GDM is associated with several adverse maternal and neonatal outcomes including increased risk of preterm birth [4], cesarean delivery [5], birth injuries [5, 6], macrosomia, hypoglycemia, and hyperbilirubinemia [7]. Long-term sequelae for the offspring include increased risk of childhood obesity [8] and type 2 diabetes [9], thereby extending the transgenerational cycle of obesity and diabetes $[9,10]$. Additionally, compared to women whose pregnancies were not complicated by GDM, those with GDM are seven times more likely to develop type 2 diabetes, especially in the first five years postpartum [11, 12]. The estimated national economic cost of GDM for clinical care of both mother and infant in 2017 was about $\$ 1.6$ billion [13].

Physical activity has been shown to improve glucose control, in part through the acute effects of contractionmediated glucose uptake into skeletal muscle [14]. Among women with GDM, previous studies have shown that an acute bout of exercise can improve blood glucose control [15-17]. One study found an improvement in postprandial blood glucose following a single bout of low intensity walking [15]. Likewise, in a study by Coe at al., women with GDM completed a supervised walking bout on a treadmill and a bout of sitting and talking, with the condition order randomized, and found improvements in post postprandial glucose with walking [17]. A a study by Avery et al. found lower blood glucose levels following low and moderate intensity aerobic exercise using cycle ergometer [16].

There is evidence that chronic adaptations to maternal physical activity during pregnancy is beneficial to maternal blood glucose regulation and long term metabolic health of offspring [18]. Two meta-analyses found that maternal exercise interventions among women during pregnancy were effective at lowering the odds of developing GDM $[19,20]$. Due to the logistic challenges of studying the impact of maternal physical activity on the long term metabolic health of offspring, longitudinal studies have been primarily conducted in rodent models. In a recent review by Kusuyama et al., 11 different rodent model studies investigating the impact of maternal exercise on adult offspring glucose metabolism were identified [18]. Of these, 8 showed that maternal exercise improved adult offspring glucose metabolism, including preventing the development of metabolic disease [18]. If these findings are applicable to humans, then exercise may be used to combat the transgenerational cycle of obesity and diabetes $[9,10]$.
Evidence-based strategies for improving physical activity and blood glucose control in women with GDM (i.e., lifestyle interventions appropriate for the clinical setting) would be useful for clinicians providing recommendations for this population. This narrative review presents the rationale for: (1) promoting physical activity in women with GDM based on current recommendations, and the scientific literature to date on physical activity interventions for blood glucose control in GDM, (2) future examination of behavioral lifestyle interventions promoting walking that are delivered via health coaching, and thus appropriate for the clinical setting.

\section{Current recommendations for physical activity during pregnancy}

Based on scientific evidence available to date, several professional organizations have published recommendations for physical activity during pregnancy [21-23]. The American College of Obstetricians and Gynecologists' (ACOG) guidelines state that "most pregnant patients can exercise and there are few maternal medical conditions in which aerobic exercise is absolutely contraindicated" [22]. Both ACOG and the U.S. Department of Health and Human Services (DHHS) [21, 22] recommend that pregnant women engage in at least $150 \mathrm{~min}$ of moderate-intensity aerobic activity per week, similar to physical activity guidelines for the general adult population [21]. ACOG specifically suggests that pregnant women should participate in both aerobic and strength conditioning exercises and recommends moderateintensity exercise for a minimum of 20 to $30 \mathrm{~min}$ per day on most or every day of the week, though guidance on strength conditioning exercises is not provided [22]. Recommendations for exercise in pregnancy by the American College of Sports Medicine (ACSM) also closely follows the guidelines for healthy adults (a minimum of $150 \mathrm{~min} /$ week of moderate intensity aerobic exercise) [23].

\section{Recommendations for physical activity in women with GDM}

After diagnosis, GDM treatment begins with medical nutrition therapy, physical activity, and, depending on pregestational weight class, weight management [24]. The Standards of Medical Care in Diabetes provides guidance on medical nutrition therapy (i.e., provision of an individualized nutrition plan) and weight management (i.e., promote weight gain according to the 2009 Institute of Medicine recommendations [25], but offer no specific advice pertaining to physical activity [24]. Similarly, ACOG acknowledges that physical activity can help lower blood glucose, but provides no explicit recommendations on physical activity for blood glucose control in women with GDM [22]. The DHHS 
recognizes the role of physical activity in blood glucose control for type 2 diabetes and recommends that adults with type 2 diabetes engage in at least $150 \mathrm{~min}$ of moderate to vigorous physical activity and two days of muscle strengthening per week (preferably in bouts spread throughout the week) [21]. However, there are no specific recommendations for women with GDM [21]. Likewise, ACSM guidelines also do not provide explicit exercise recommendations for women with GDM per se, but instead suggest that an exercise routine should be instituted after discussion with a health care provider and individualized based on health condition, symptoms, and fitness level [23].

In 2010, the American Diabetes Association (ADA) and American College of Sports Medicine (ACSM) disagreed as to the quality of the scientific evidence supporting moderate intensity exercise for lowering blood glucose levels in GDM [26]. Both the ADA and ACSM gave the evidence a ' $\mathrm{B}$ ' rating [26]. However, ADA's rating of ' $\mathrm{B}$ ' indicates that evidence was obtained from 'well-conducted cohort or case-control studies' while ACSM's rating of 'B' indicates that evidence was based on limited data from Randomized Controlled trials (RCTs) [26]. More recently, in a 2016 position statement, the ADA suggested that exercise could improve glycemic control and recommended that women with GDM complete 20 to 30 minutes of moderate-intensity exercise on most or all days of the week, with a rating of ' $\mathrm{B}$ ' for the quality of evidence [27] (i.e., again, evidence to support obtained from 'well-conducted cohort or case-control studies') [28]. Overall, current physical activity recommendations for women with GDM do not go beyond basic public health recommendations for pregnant and non-pregnant adults alike. Given the added demands of managing GDM during pregnancy, the provision of a more detailed, evidence-based physical activity prescription, in conjunction with support for health behavior change, may be needed to increase physical activity levels and improve health outcomes in this population.

\section{Methods}

To review the scientific literature in this area, a primary literature search was independently completed by two authors (OO and BR) using the following keywords in PubMed: "physical activity" AND "exercise" AND "gestational diabetes" AND "treatment" NOT "prevention". Additional studies were identified by searching all references cited in articles identified in our search. Original research studies were retained for inclusion in this review if: (a) the study population was women with GDM, (b) exposure/intervention was exercise/physical activity (i.e. independent of diet or medication), and (c) the outcome(s) included a measure of glycemic control (fasting blood glucose, postprandial blood glucose, overall glycemic control, pre, and post-exercise blood glucose, random blood glucose and/or insulin requirement). Figure 1 presents a summary of the search. The primary literature search yielded 296 abstracts from which we identified 26 articles that presented data on physical activity for GDM management. Searching the references of these 26 articles identified two additional articles, and one additional article was included from the previous work of one of the co-authors (SE), for a total of 29

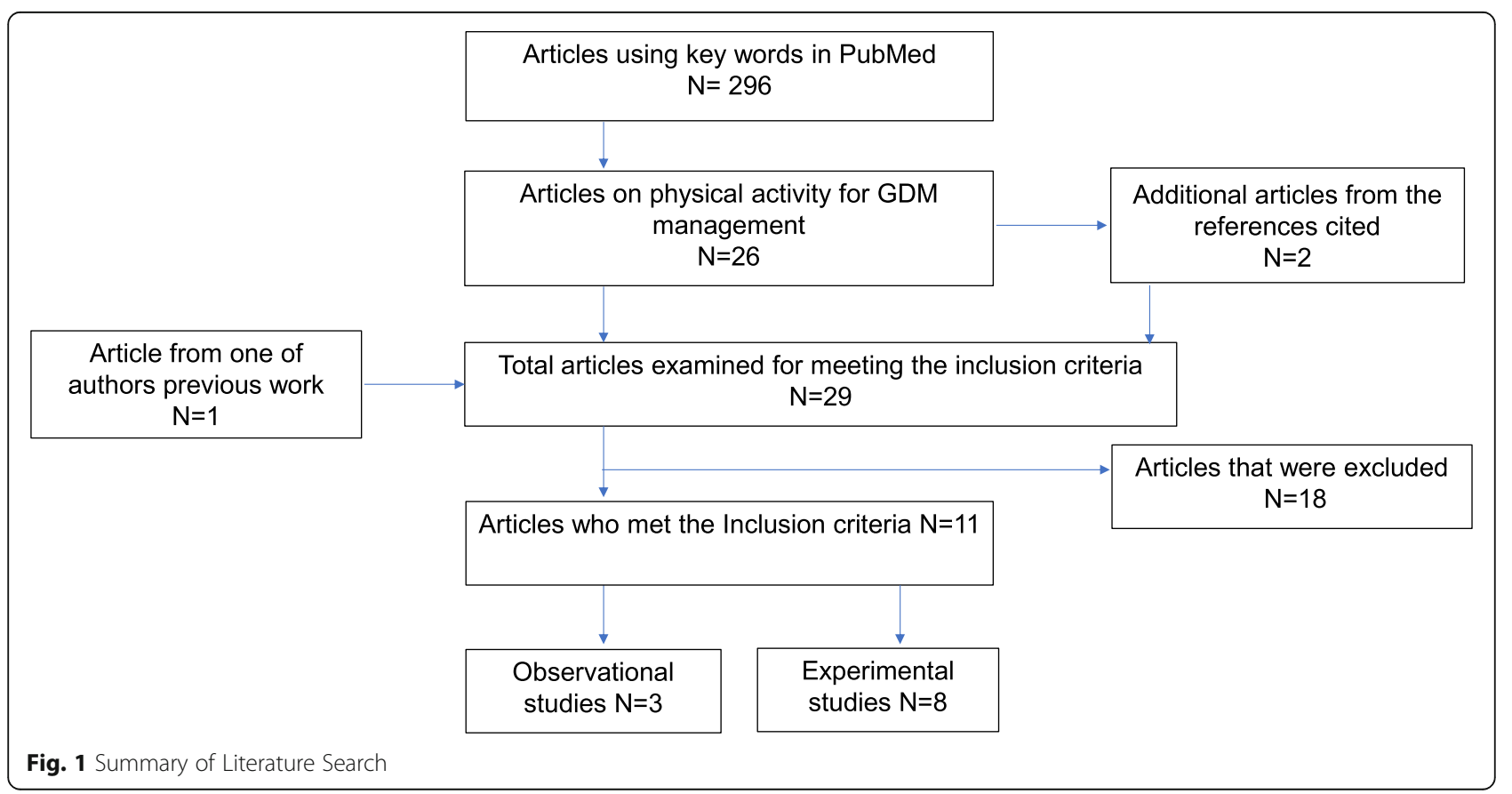


articles. Articles were excluded if they were reviews $(N=13)$, controls were not women with GDM $(N=1)$, exercise intervention was acute $(N=3)$ and outcome measures were not related to glucose control $(N=1)$. Eleven studies met our inclusion criteria $(N=3$ observational [29-31] and $N=8$ experimental studies [32-39].

\section{Results}

Findings from the observational studies [29-31] suggest that physical activity improves glycemic control in women with gestational diabetes. Evidence from a cohort study of over 900 women with GDM found that moderate-intensity physical activity, as self-reported on the Pregnancy Physical Activity Questionnaire, was significantly associated with optimal glycemic control, defined as $\geq 80 \%$ of self-monitored capillary glucose values meeting clinical targets [30]. In a small study of 24 women with GDM, there was an inverse association between daily steps (objectively assessed by device) and random blood glucose [31]. The authors also reported significantly lower random blood glucose among those who completed $\geq 6000$ steps per day [31]. Another small study of 30 women with GDM showed significant improvement in fasting and postprandial glucose levels and lower insulin requirements following participation in low-intensity walking sessions [29].

The results of the experimental studies also suggest that physical activity improves blood glucose control in women with GDM [32-39] (Table 1). It is noteworthy to mention that the outcomes examined in experimental studies varied considerably. Among the experimental studies that found improvement in glycemic control, one measured fasting blood glucose [37], three measured postprandial blood glucose [32, 33, 38], two measured glycated hemoglobin (HbA1c) [32, 37], and two reported insulin requirement $[35,36]$.

The physical activity interventions utilized in the experimental studies reviewed were almost entirely supervised [37, 39] or a combination of supervised and unsupervised exercise sessions [33-35, 38], and thus likely difficult to translate to the health care system and real life situations. We present the characteristics of the eight experimental studies reviewed for this paper in Table 1. Among the exercise interventions for the eight experimental studies identified, two utilized aerobic exercises [37, 39], two utilized resistance exercise [35, 36], three utilized walking in combination with aerobic and/ or resistance exercises [33, 34, 38]. Only one study included walking alone and was completely unsupervised [32]. Overall, four of the experimental studies examined the effect of exercise intervention that included some degree of walking [32-34, 38]. Notably, Bo et al. investigated the effects of a completely unsupervised walking intervention in a sample of 200 women with GDM [32].
The authors reported an improvement in postprandial glucose and glycated hemoglobin in response to moderate intensity walking with exercise intervention that included unsupervised moderate intensity walking for $20 \mathrm{~min}$ per day (or $140 \mathrm{~min} /$ week) [32]. This exercise intervention is unique in that it could easily be prescribed in the clinical setting and achieved in the reallife setting.

\section{Discussion \\ Walking: the preferred physical activity during pregnancy and ideal for GDM management}

Physical activity levels in pregnant women are lower than those in non-pregnant populations [40]. The prevalence of pregnant women achieving the higher threshold of ACOG's 2015 recommendation of $\geq 150 \mathrm{~min}$ of physical activity on $\geq 5$ days per week, as derived from $\mathrm{Na}$ tional Health and Nutrition Examination Survey (NHAN ES) data between 2007 and 2014 was only approximately $13 \%$ [41]. The intensity and duration of physical activity are typically reduced with the recognition of pregnancy and/or as pregnancy advances [42], and GDM management is limited to the third trimester.

Previous studies have described barriers to physical activity in pregnant women which include lack of time, unfavorable weather, work schedule, childcare, lack of support, and motivation [43-45]. Walking is the most frequently reported modality of physical activity in pregnant women [46]. Walking may offer a potential solution to barriers such as lack of time (e.g., can be integrated into daily activities), childcare responsibilities (e.g., can be done with a stroller or together with children), unfavorable weather (e.g., can be done indoors) and lack of exercise equipment [45]. Three out of the studies that included some degree of walking in the intervention showed promising results to support walking for glycemic control in GDM [32, 33, 38]. The exercise interventions in these studies included unsupervised walking daily for a minimum of 6 weeks [38], unsupervised walking twice a week for about 6 weeks [33], unsupervised walking $20 \mathrm{~min}$ in a day or $140 \mathrm{~min}$ in a week [32]. There is a paucity of studies examining the effects of behavioral lifestyle interventions promoting unsupervised walking in women with GDM. To improve on current guidelines for GDM management, further investigation of behavioral lifestyle interventions promoting walking is warranted, specifically interventions appropriate for clinical and real life settings [32].

\section{Future research: interventions appropriate for the health care delivery system}

Behavioral interventions delivered via health coaching have successfully been implemented during pregnancy and the postpartum period in the health care delivery 
Table 1 Characteristics of the experimental studies reviewed

\begin{tabular}{|c|c|c|c|c|c|c|}
\hline Author & Study Design & $\begin{array}{l}\text { Sample } \\
\text { size }\end{array}$ & Intervention condition & $\begin{array}{l}\text { Control } \\
\text { condition }\end{array}$ & Outcomes & Findings \\
\hline \multicolumn{7}{|c|}{ Walking alone } \\
\hline $\begin{array}{l}\text { Bo et al. } \\
2014 \text { [32] } \\
\text { Italy }\end{array}$ & $\begin{array}{l}2 \times 2 \text { factorial design, } \\
\text { baseline at } 24-26 \text { weeks } \\
\text { gestation, follow up } \\
\text { evaluation at } 38 \text { th week } \\
\text { or before delivery. } \\
\text { Four different participant } \\
\text { groups: } \\
- \text { D: Dietary } \\
\text { recommendations only } \\
\text {-B: Behavioral dietary } \\
\text { recommendations only } \\
\text {-E: Exercise only } \\
\text {-BE: Behavioral dietary } \\
\text { recommendations, and } \\
\text { exercise. }\end{array}$ & 200 & $\begin{array}{l}\text { Supervision: No } \\
\text { Frequency: Every day } \\
\text { Intensity: } 12-14 \text { on the } \\
\text { Borg Rating of Perceived } \\
\text { Exertion scale } \\
\text { Type: Walking } \\
\text { Duration: } 20 \mathrm{~min} / \text { day or } \\
140 \mathrm{~min} / \text { week }\end{array}$ & $\begin{array}{l}\text { Behavioral } \\
\text { dietary } \\
\text { recommendation }\end{array}$ & $\begin{array}{l}\text { Primary outcome: } \\
\text { Fasting blood glucose } \\
\text { Secondary outcomes: } \\
\text { Postprandial glucose, } \\
\text { Hemoglobin A1c } \\
\text { (HbA1c), Insulin, } \\
\text { Homeostasis-Model- } \\
\text { Assessment-Insulin Re- } \\
\text { sistance (HOMAIR) }\end{array}$ & $\begin{array}{l}\text { Adjusted difference in } \\
\text { postprandial glucose } \\
\text { (mg/dl) for exercise } \\
\text { versus control was - } \\
11.1(95 \% \text { Cl: - } 16.1,-0.2 \text {; } \\
p<0.001) \text {. } \\
\text { Adjusted difference in } \\
\text { HbA1c (\%) for exercise } \\
\text { versus control was }-0.3 \\
(95 \% \text { Cl: }-0.4,-0.2) ; p< \\
0.001) \text {. } \\
\text { No significant difference } \\
\text { in Fasting glucose, Log- } \\
\text { fasting insulin, and Log- } \\
\text { HOMA-IR. }\end{array}$ \\
\hline
\end{tabular}

Walking combined with other Aerobic and/or Resistance Exercises

$\begin{array}{ll}\text { et al. } 1997 & \text { gestation, follow-up } \\ \text { [34] } & \text { measurements 4-weeks }\end{array}$

USA later

Halse

$\mathrm{RCT}$, enrolled 26-30

40

et al. 2014 weeks gestation, follow-

[33] up measurements 6-

Australia weeks later
Supervision: Partly

Frequency: 3-4 times/

week till the end of

pregnancy

Intensity: $70 \%$ of

calculated maximal heart

rate

Type: Cycle ergometer for supervised, either walking or cycle ergometer for unsupervised (most participants chose walking for unsupervised)

Duration: $30 \mathrm{~min}$ (this included a 5 min warmup and 5 min cool-down before/after a $20 \mathrm{~min}$ session)

Supervision: Partly, though all exercise occurring at home Frequency: 3 supervised and 2 unsupervised per week for approximately 6 weeks

Intensity: 5 min warm-up at 9-11 RPE (Borg scale) followed by phases of continuous moderateintensity (12-14 RPE) and interval bouts higher intensity (15-15 RPE) mixed with lower intensity (9-11 RPE). Ends with 5-10 min cool-down at 9-11 RPE

Type: Upright stationary cycle ergometer for supervised. Not specified for unsupervised sessions, depends on the participant's choice (walking and cycling were the most commonly selected).

Duration: Range from 25
Dietary therapy Hemoglobin A1C, and maintaining fasting and postprandial current physical blood glucose. activity level.

Conventional Fasting blood glucose, GDM treatment. Postprandial blood glucose, glycosylated hemoglobin and insulin levels
Mean postprandial glucose was significantly lower in exercise group compared with control $(P=0.046)$

No significant difference in daily fasting glucose, $\mathrm{HbA} 1 \mathrm{C}$, fasting glucose and insulin levels after Oral Glucose Tolerance Test. 
Table 1 Characteristics of the experimental studies reviewed (Continued)

\begin{tabular}{|c|c|c|c|c|c|c|}
\hline Author & Study Design & $\begin{array}{l}\text { Sample } \\
\text { size }\end{array}$ & Intervention condition & $\begin{array}{l}\text { Control } \\
\text { condition }\end{array}$ & Outcomes & Findings \\
\hline & & & $\begin{array}{l}\text { to } 45 \text { min according to } \\
\text { participant ability and } \\
\text { progression. }\end{array}$ & & & \\
\hline $\begin{array}{l}\text { Sklempe } \\
\text { Kokic et al. } \\
2018 \text { [38] } \\
\text { Croatia }\end{array}$ & $\begin{array}{l}\text { RCT, enrolled } \leq 30 \text { weeks } \\
\text { gestation, follow up data } \\
\text { on glucose levels } \\
\text { collected monthly /bi- } \\
\text { monthly till end of } \\
\text { pregnancy ( } 38-40 \\
\text { weeks; data abstracted } \\
\text { following childbirth) }\end{array}$ & 42 & $\begin{array}{l}\text { Supervision: Partly } \\
\text { Frequency: } 2 \text { times/ week } \\
\text { of supervised session and } \\
\text { unsupervised walking } \\
\text { daily for a minimum of } 6 \\
\text { weeks } \\
\text { Intensity: 13-14 on the } \\
\text { Borg Rating of Perceived } \\
\text { Exertion scale for aerobic } \\
\text { and resistance exercises } \\
\text { parts } \\
\text { Type: Unsupervised } \\
\text { walking plus supervised } \\
\text { session which includes } \\
\text { aerobic (on treadmill), } \\
\text { resistance, pelvic floor and } \\
\text { stretching, relaxation } \\
\text { Duration: } 30 \text { min for } \\
\text { unsupervised walking, 50- } \\
55 \text { min of the supervised } \\
\text { session }\end{array}$ & $\begin{array}{l}\text { Standard } \\
\text { Antenatal care } \\
\text { for GDM }\end{array}$ & $\begin{array}{l}\text { Fasting and } \\
\text { postprandial glucose } \\
\text { levels at the end of } \\
\text { pregnancy }\end{array}$ & $\begin{array}{l}\text { Mean postprandial } \\
\text { glucose was lower for } \\
\text { exercise group ( } 4.66 \pm \\
0.46 \mathrm{mmol} / \mathrm{L}) \text { vs. control } \\
\text { group }(5.30 \pm 0.47 \mathrm{mmol} / \\
\mathrm{L}) ;(p<0.001) \\
\text { No significant differences } \\
\text { in fasting blood glucose. }\end{array}$ \\
\hline
\end{tabular}

\section{Other Aerobic Exercises}

$\begin{array}{ll}\text { Bung } & \text { RCT, enrolled 27-32 } \\ \text { et al. 1991 } & \text { weeks gestation, blood } \\ \text { [39] } & \begin{array}{l}\text { glucose determined } \\ \text { USA }\end{array} \\ & \text { weekly thereafter. } \\ \text { Jovanovic- } & \text { RCT, } \\ \text { Peterson } & \begin{array}{l}\text { Gestational age at } \\ \text { et al. 1989 }\end{array} \\ \text { enrollment unknown, } \\ \text { [37]USA } & \begin{array}{l}\text { weekly follow up for } 6 \\ \text { weeks }\end{array}\end{array}$

\section{Resistance Training}

deBarros et al. 2010 [36] Brazil
$\mathrm{RCT}$, enrolled sedentary women at 24-34 weeks gestation, followed to end of pregnancy
Insulin therapy

Supervision: Yes Intensity: $50 \%$ VO2 max Type: Recumbent bicycle Duration: $45 \mathrm{~min}$

Supervision: Yes Frequency: 3 times/week Intensity: Moderate intensity

Type: Arm ergometer training

Duration: 20 min for 6 weeks

Supervision: Partly
Frequency: 3 times/week Intensity: Perceived exertion scale "somewhat heavy"

Description: Resistance band to target main muscle groups (i.e., stations for chest, back, biceps, triceps, deltoid, quadriceps, thigh, and calf muscles); performed 15 repetitions at each station, with a minimum resting period of $30 \mathrm{~s}$ and $\mathrm{a}$ maximum of $1 \mathrm{~min}$ in between stations. In weeks 1 and 2, underwent 2 circuit series, then 3 circuit series from week 3 to end of pregnancy

Supervision: Partly Frequency: 3 times/week Intensity: felt "somewhat
Mean weekly fasting plasma glucose

Fasting glucose levels, post prandial glucose levels, glycosylated hemoglobin
No statistical differences between exercise and Insulin subjects were observed in blood glucose measurements.

Significant difference in fasting and glycated Hemoglobin.

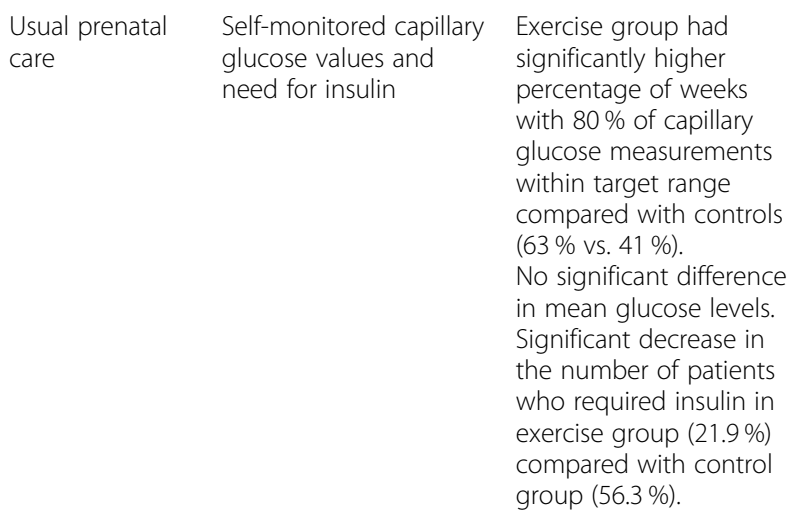

significantly higher percentage of weeks with $80 \%$ of capillary glucose measurements within target range compared with controls (63\% vs. $41 \%$ ). No significant difference in mean glucose levels. Significant decrease in the number of patients who required insulin in exercise group (21.9\%) compared with control group (56.3\%).

Significant difference in amount of insulin required (units $/ \mathrm{kg}$ ) 
Table 1 Characteristics of the experimental studies reviewed (Continued)

\begin{tabular}{|c|c|c|c|c|c|c|}
\hline Author & Study Design & $\begin{array}{l}\text { Sample } \\
\text { size }\end{array}$ & Intervention condition & $\begin{array}{l}\text { Control } \\
\text { condition }\end{array}$ & Outcomes & Findings \\
\hline Canada & pregnancy & & $\begin{array}{l}\text { hard" } \\
\text { Description: Anchored } \\
\text { rubber tubing to } \\
\text { complete } 8 \text { exercises [i.e., } \\
\text { plies (squats with outward } \\
\text { facing knees), military } \\
\text { press, knee extension, } \\
\text { hamstring curl, bench } \\
\text { press, lateral pull down, } \\
\text { seated row, and triceps } \\
\text { press] with < } 1 \text { min rest in } \\
\text { between. Weeks } 1 \text { and } 2 \\
\text { included } 2 \text { sets of } 15 \\
\text { repetitions for each } \\
\text { exercise; } 3 \text { sets of } 15 \\
\text { repetitions for each in } \\
\text { week } 3 ; 3 \text { sets of } 20 \\
\text { repetitions for each from } \\
\text { week } 4 \text { to end of } \\
\text { pregnancy }\end{array}$ & & $\begin{array}{l}\text { Latency to insulin } \\
\text { treatment and amount } \\
\text { of insulin }\end{array}$ & $\begin{array}{l}\text { (diet alone, } 0.48 \pm 0.3 \\
\text { versus diet and exercise, } \\
0.22 \pm 0.2 \text { ) } \\
\text { Significant difference in } \\
\text { latency (weeks) to insulin } \\
\text { requirement (diet alone, } \\
1.11 \pm 0.8 \text { versus diet and } \\
\text { exercise, } 3.71 \pm 3.1 \text { ) }\end{array}$ \\
\hline
\end{tabular}

system [47-49]. A pilot feasibility RCT that tested a Diabetes Prevention Program (DPP) based lifestyle intervention of diet and physical activity for weight management delivered by trained dieticians demonstrated that such a behavioral lifestyle intervention can be successfully implemented in women with GDM [47]. The findings of a large cluster-randomized trial showed that women with recent GDM who received the DPP-based lifestyle intervention delivered by a health coach (via telephone) were more likely to achieve postpartum weight loss goals [49]. Results from a trial conducted among pregnant women with overweight/obesity reported improvements in gestational weight gain with a similar lifestyle intervention delivered via telehealth [48]. The underlying theory behind these behavioral interventions delivered through health coaching is based on Bandura's social cognitive theory $[50,51]$ and the Transtheoretical model $[51,52]$, that include goal-setting, self-monitoring, and feedback on progress towards behavior goals [51].

Health education and promotion within a 'coaching' context show great promise in terms of enhancing wellbeing and facilitating the achievement of health- or lifestyle-related goals $[53,54]$. Individuals trained in health coaching have the professional skills needed to elicit sustainable health-related behavior change by improving patient engagement and activation [54]. The strong argument for the health coaching approach lies in its potential to prompt behavioral changes $[54,55]$ (such as increasing physical activity) but, importantly and distinctly, the ease of its translation to the health care system [49].

The idea of health coaching for behavior change, particularly in GDM, is not entirely new to the health care system. ADA recommendations for the clinical management of GDM involves medical nutrition therapy, usually delivered by a diabetes educator who is often a registered dietician [24]. Medical nutrition therapy traditionally involves the creation of a personalized nutrition plan as well as monitoring of carbohydrate intake (e.g., counting grams) and feedback/adjustment on this over time to meet clinic targets for capillary glucose values [24]. Based on the theory employed by successful behavioral intervention trials for weight management in pregnancy/postpartum (that included a physical activity component) [47-49, 51], future trials should examine behavioral physical activity interventions for GDM that are delivered by a lifestyle coach and utilize goal setting, monitoring, and feedback.

Given that walking is the most common physical activity modality in pregnant women [40, 45], a behavioral physical activity intervention that promoted walking could use the duration of walking and/or step count achieved during walking to set goals, monitor, and receive feedback over time, similar to goals set for grams of carbohydrate in the context of medical nutrition therapy. Consumer-based wearable devices with the ability to track physical activity (including walking duration and steps) have been shown to increase physical activity levels outside of pregnancy [56]. Trials of behavioral interventions promoting walking for GDM management, with the health behavior change strategy of goal setting potentially supported by wearable technology, are needed to inform the development of a physical activity prescription that can be easily implemented in health care delivery systems.

\section{Conclusions}

In conclusion, scientific evidence strongly suggests that physical activity is beneficial for GDM management. 
However, further research is needed to identify detailed physical activity prescriptions that are feasible for delivery in the clinical setting and may be integrated into the lifestyle counseling already being utilized for diet. Future research should focus on behavioral physical activity interventions delivered via health coaching and may include the use of physical activity tracking devices to support goal setting, monitoring, and feedback; these strategies are already used in the clinical care of women with GDM.

\section{Acknowledgements}

Not Applicable.

\section{Authors' contribution}

SE conceived the idea and supervised the project. $\mathrm{OO}$ and BR performed the literature search. $\mathrm{OO}, \mathrm{BR}$, and SE drafted the manuscript. JM, KF, and NZ reviewed the manuscript and provided critical feedback. All authors read and approved the final manuscript

\section{Funding}

Dr. Ehrlich is supported by grant K01 DK105106 from the National Institute of Diabetes and Digestive and Kidney Diseases. Funding for open access to this research was provided by the University of Tennessee's Open Publishing Support Fund.

\section{Availability of data and materials}

Data sharing is not applicable to this article as no datasets were generated or analyzed during the current study.

\section{Ethics approval and consent to participate}

Not Applicable.

\section{Consent for publication}

Not Applicable.

\section{Competing interests}

The authors declare that they have no competing interests.

\section{Author details}

'Department of Public Health, The University of Tennessee, 369 HPER, 1914 Andy Holt Ave., TN 37996 Knoxville, USA. ${ }^{2}$ Department of Obstetrics and Gynecology, Graduate School of Medicine, The University of Tennessee, Knoxville, TN, USA.

Received: 15 January 2021 Accepted: 15 April 2021

Published online: 25 April 2021

\section{References}

1. American College of Obstetricians Gynecologists. ACOG practice bulletin no. 190: gestational diabetes mellitus. Obstet Gynecol. 2018;131(2):e49-64.

2. Deputy NP, Kim SY, Conrey EJ, Bullard KM. Prevalence and changes in preexisting diabetes and gestational diabetes among women who had a live birth-United States, 2012-2016. Morb Mortal Wkly Rep. 2018;67(43): 1201.

3. Deputy NP, Dub B, Sharma AJ. Prevalence and trends in prepregnancy normal weight—48 states, New York City, and District of Columbia, 20112015. Morb Mortal Wkly Rep. 2018;66(5152):1402.

4. Hedderson MM, Ferrara A, Sacks DA. Gestational diabetes mellitus and lesser degrees of pregnancy hyperglycemia: association with increased risk of spontaneous preterm birth. Obstet Gynecol. 2003;102(4):850-6.

5. Landon MB, Spong CY, Thom E, Carpenter MW, Ramin SM, Casey B, et al. A multicenter, randomized trial of treatment for mild gestational diabetes. $N$ Engl J Med. 2009:361(14):1339-48

6. Crowther CA, Hiller JE, Moss JR, MCPhee AJ, Jeffries WS, Robinson JS. Effect of treatment of gestational diabetes mellitus on pregnancy outcomes. N Engl J Med. 2005;352(24):2477-86.
7. Ferrara A, Weiss N, Hedderson M, Quesenberry C, Selby J, Ergas I, et al. Pregnancy plasma glucose levels exceeding the American Diabetes Association thresholds, but below the National Diabetes Data Group thresholds for gestational diabetes mellitus, are related to the risk of neonatal macrosomia, hypoglycaemia and hyperbilirubinaemia. Diabetologia. 2007;50(2):298-306.

8. Ehrlich SF, Hedderson MM, Xu F, Ferrara A. Diagnostic thresholds for pregnancy hyperglycemia, maternal weight status and the risk of childhood obesity in a diverse Northern California cohort using health care delivery system data. PloS one. 2019;14(5):e0216897.

9. Dabelea $\mathrm{D}$, Crume T. Maternal environment and the transgenerational cycle of obesity and diabetes. Diabetes. 2011;60(7):1849-55.

10. Catalano PM. Obesity and Pregnancy - The Propagation of a Viscous Cycle? The Journal of Clinical Endocrinology Metabolism. 2003;88(8):3505-6.

11. Bellamy L, Casas J-P, Hingorani AD, Williams D. Type 2 diabetes mellitus after gestational diabetes: a systematic review and meta-analysis. The Lancet. 2009:373(9677):1773-9.

12. Kim C, Newton KM, Knopp RH. Gestational diabetes and the incidence of type 2 diabetes: a systematic review. Diabetes Care. 2002;25(10):1862-8.

13. Dall TM, Yang W, Gillespie K, Mocarski M, Byrne E, Cintina I, et al. The economic burden of elevated blood glucose levels in 2017: diagnosed and undiagnosed diabetes, gestational diabetes mellitus, and prediabetes. Diabetes Care. 2019:42(9):1661-8.

14. Rose AJ, Richter EA. Skeletal muscle glucose uptake during exercise: how is it regulated? Physiology. 2005;20(4):260-70.

15. García-Patterson A, Martín E, Ubeda J, María MA, de Leiva A, Corcoy R. Evaluation of light exercise in the treatment of gestational diabetes. Diabetes Care. 2001;24(11):2006-7.

16. Avery $M$, Walker A. Acute effect of exercise on blood glucose and insulin levels in women with gestational diabetes. Journal of Maternal-Fetal Medicine. 2001;10(1):52-8.

17. Coe DP, Conger SA, Kendrick JM, Howard BC, Thompson DL, Bassett DR Jr, et al. Postprandial walking reduces glucose levels in women with gestational diabetes mellitus. Appl Physiol Nutr Metab. 2018;43(5):531-4.

18. Kusuyama J, Alves-Wagner AB, Makarewicz NS, Goodyear L. Effects of maternal and paternal exercise on offspring metabolism. Nat Metab. 2020;2(9):858-72.

19. Ming W-K, Ding W, Zhang CJ, Zhong L, Long $Y$, Li Z, et al. The effect of exercise during pregnancy on gestational diabetes mellitus in normalweight women: a systematic review and meta-analysis. BMC Pregnancy Childbirth. 2018:18(1):1-9.

20. Davenport MH, Ruchat S-M, Poitras VJ, Garcia AJ, Gray CE, Barrowman N, et al. Prenatal exercise for the prevention of gestational diabetes mellitus and hypertensive disorders of pregnancy: a systematic review and metaanalysis. Br J Sports Med. 2018;52(21):1367-75.

21. U.S. Department of Health and Human Services. Physical Activity Guidelines for Americans, 2nd edition. Washington, DC: U.S.: Department of Health and Human Services; 2018

22. The American College of Obstetricians and Gynecologists Committee on Obstetric Practice. Physical Activity and Exercise During Pregnancy and the Postpartum Period: ACOG Committee Opinion, Number 804. Obstet Gynecol. 2020;135(4):e178-e88.

23. American College of Sports Medicine. ACSM's guidelines for exercise testing and prescription: Wolters Kluwer; 2018.

24. American Diabetes Association. Management of Diabetes in Pregnancy: Standards of Medical Care in Diabetes-2020. Diabetes Care. 2020:43(Suppl 1):183-S92.

25. Institute of Medicine, National Research Council Committee to Reexamine IOM Pregnancy Weight Guidelines. Weight Gain During Pregnancy: Reexamining the Guidelines. Rasmussen KM, Yaktine AL, editors. Washington (DC): National Academies Press (US), National Academy of Sciences; 2009.

26. Colberg SR, Sigal RJ, Fernhall B, Regensteiner JG, Blissmer BJ, Rubin RR, et al. Exercise and type 2 diabetes: the American College of Sports Medicine and the American Diabetes Association: joint position statement executive summary. Diabetes Care. 2010;33(12):2692-6.

27. Colberg SR, Sigal RJ, Yardley JE, Riddell MC, Dunstan DW, Dempsey PC, et al. Physical activity/exercise and diabetes: a position statement of the American Diabetes Association. Diabetes Care. 2016;39(11):2065-79.

28. American Diabetes Association. Introduction: Standards of Medical Care in Diabetes—2020. Diabetes Care. 2020;43(Suppl 1):1.

29. Davenport MH, Mottola MF, McManus R, Gratton R. A walking intervention improves capillary glucose control in women with gestational diabetes mellitus- a pilot study. Appl Physiol Nutr Metab. 2008;33(3):511-7. 
30. Ehrlich S, Hedderson M, Brown S, Sternfeld B, Chasan-Taber L, Feng J, et al. Moderate intensity sports and exercise is associated with glycaemic control in women with gestational diabetes. Diabetes Metab. 2017:43(5):416-23.

31. Hayashi A, Oguchi H, Kozawa Y, Ban Y, Shinoda J, Suganuma N. Daily walking is effective for the management of pregnant women with gestational diabetes mellitus. J Obstet Gynaecol Res. 2018;44(9):1731-8.

32. Bo S, Rosato R, Ciccone G, Canil S, Gambino R, Poala CB, et al. Simple lifestyle recommendations and the outcomes of gestational diabetes. A $2 \times 2$ factorial randomized trial. Diabetes Obesity Metabolism. 2014;16(10):1032-5.

33. Halse RE, Wallman KE, Newnham JP, Guelfi KJ. Home-based exercise training improves capillary glucose profile in women with gestational diabetes. Med Sci Sports Exerc. 2014;46(9):1702-9.

34. Avery MD, Leon AS, Kopher RA. Effects of a partially home-based exercise program for women with gestational diabetes. Obstet Gynecol. 1997;89(1): 10-5.

35. Brankston GN, Mitchell B, Ryan EA, Okun NB. Resistance exercise decreases the need for insulin in overweight women with gestational diabetes mellitus. Am J Obstet Gynecol. 2004;190(1):188-93.

36. de Barros MC, Lopes MA, Francisco RP, Sapienza AD, Zugaib M. Resistance exercise and glycemic control in women with gestational diabetes mellitus. Am J Obstet Gynecol. 2010:203(6):556. e1-. e6.

37. Jovanovic-Peterson L, Durak EP, Peterson CM. Randomized trial of diet versus diet plus cardiovascular conditioning on glucose levels in gestational diabetes. Am J Obstet Gynecol. 1989;161(2):415-9.

38. Sklempe Kokic I, Ivanisevic M, Biolo G, Simunic B, Kokic T, Pisot R. Combination of a structured aerobic and resistance exercise improves glycaemic control in pregnant women diagnosed with gestational diabetes mellitus. A randomised controlled trial. Women Birth. 2018;31(4):e232-e8.

39. Bung P, Artal R, Khodiguian N, Kjos S. Exercise in gestational diabetes: an optional therapeutic approach? Diabetes. 1991;40(Supplement 2):182-5.

40. Evenson KR, Savitz A, Huston SL. Leisure-time physical activity among pregnant women in the US. Paediatr perinat epidemiol. 2004;18(6):400-7.

41. Hesketh KR, Evenson KR. Prevalence of US pregnant women meeting 2015 ACOG physical activity guidelines. Am J Prev Med. 2016;51(3):e87-e9.

42. Galliano LM, Del Vecchio AH, Silvani J, Façanha C, Del Vecchio FB. Physical activity level in women with gestational diabetes mellitus: Lifestyle INtervention for Diabetes prevention After pregnancy (LINDA-Brasil) study. J Diabetes. 2019;11(6):457-65.

43. Evenson KR, Moos M-K, Carrier K, Siega-Riz AM. Perceived barriers to physical activity among pregnant women. Matern Child Health J. 2009:13(3):364.

44. Cramp AG, Bray SR. A prospective examination of exercise and barrier selfefficacy to engage in leisure-time physical activity during pregnancy. Ann Behav Med. 2009;37(3):325-34

45. Connolly CP, Conger SA, Montoye AH, Marshall MR, Schlaff RA, Badon SE, et al. Walking for health during pregnancy: A literature review and considerations for future research. J Sport Heal Sci. 2019;8(5):401-11.

46. Evenson KR, Wen F. National trends in self-reported physical activity and sedentary behaviors among pregnant women: NHANES 1999-2006. Prev Med. 2010;50(3):123-8.

47. Ferrara A, Hedderson MM, Albright CL, Ehrlich SF, Quesenberry CP, Peng $T$, et al. A pregnancy and postpartum lifestyle intervention in women with gestational diabetes mellitus reduces diabetes risk factors: a feasibility randomized control trial. Diabetes Care. 2011:34(7):1519-25.

48. Ferrara A, Hedderson MM, Brown SD, Ehrlich SF, Tsai A-L, Feng J, et al. A telehealth lifestyle intervention to reduce excess gestational weight gain in pregnant women with overweight or obesity (GLOW): a randomised, parallelgroup, controlled trial. Lancet Diabetes Endocrinol. 2020;8(6):490-500.

49. Ferrara A, Hedderson MM, Brown SD, Albright CL, Ehrlich SF, Tsai A-L, et al. The comparative effectiveness of diabetes prevention strategies to reduce postpartum weight retention in women with gestational diabetes mellitus: the Gestational Diabetes' Effects on Moms (GEM) cluster randomized controlled trial. Diabetes Care. 2016;39(1):65-74.

50. Bandura A. Social foundations of thought and action: a social cognitive theory. Englewood Cliffs: Prentice-Hall; 1986.

51. Brown SD, Hedderson MM, Ehrlich SF, Galarce MN, Tsai A-L, Quesenberry $C P$, et al. Gestational weight gain and optimal wellness (GLOW): rationale and methods for a randomized controlled trial of a lifestyle intervention among pregnant women with overweight or obesity. BMC Pregnancy Childbirth. 2019;19(1):145

52. Prochaska JO, DiClemente CC. Common processes of self-change in smoking, weight control and psychological distress. In: Shiffman S, Wills T, editors. Coping and Substance Use: A conceptual framework. New York: Academic Press; 1985. pp. 345-63.

53. Office of the Surgeon General. Department of Health and Human Services. National Prevention Council, National Prevention Strategy. https://www.hhs. gov/sites/default/files/disease-prevention-wellness-report.pdf. 2011. Accessed 12 Dec 2020.

54. Schmittdiel JA, Adams SR, Goler N, Sanna RS, Boccio M, Bellamy DJ, et al. The impact of telephonic wellness coaching on weight loss: A "Natural Experiments for Translation in Diabetes (NEXT-D)" study. Obesity (Silver Spring). 2017;25(2):352-6.

55. Smith LL, Lake NH, Simmons LA, Perlman A, Wroth S, Wolever RQ Integrative health coach training: A model for shifting the paradigm toward patient-centricity and meeting new national prevention goals. Global advances in health medicine. 2013;2(3):66-74.

56. Kang M, Marshall SJ, Barreira TV, Lee J-O. Effect of pedometer-based physical activity interventions: a meta-analysis. Res Q Exerc Sport. 2009;80(3): $648-55$

\section{Publisher's Note}

Springer Nature remains neutral with regard to jurisdictional claims in published maps and institutional affiliations.
Ready to submit your research? Choose BMC and benefit from:

- fast, convenient online submission

- thorough peer review by experienced researchers in your field

- rapid publication on acceptance

- support for research data, including large and complex data types

- gold Open Access which fosters wider collaboration and increased citations

- maximum visibility for your research: over $100 \mathrm{M}$ website views per year

At $\mathrm{BMC}$, research is always in progress.

Learn more biomedcentral.com/submissions 